Malaysian Journal of Social Sciences and Humanities (MJSSH), Volume 6, Issue 10, (page 1 - 14), 2021

DOI: https://doi.org/10.47405/mjssh.v6i10.1048

\begin{tabular}{|c|c|}
\hline $\sin =1$ & Malaysian Journal of Social Sciences and Humanities (MJSSH) \\
\hline $\begin{array}{l}\text { Malaysian Journal of } \\
\text { Social silences and }\end{array}$ & Volume 6, Issue 10, October 2021 \\
\hline 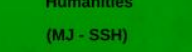 & e-ISSN : 2504-8562 \\
\hline & $\begin{array}{l}\text { Journal home page: } \\
\text { www.msocialsciences.com }\end{array}$ \\
\hline
\end{tabular}

\title{
Sarawak dan Federalisme Di Bawah Kepimpinan Adenan Satem, 2014-2017
}

\author{
Fredrick Michael Gawan ${ }^{1}$, Arnold Puyok ${ }^{1}$ \\ ${ }^{1}$ Fakulti Sains Sosial dan Kemanusiaan, Universiti Malaysia Sarawak (UNIMAS), Malaysia \\ Correspondence: Fredrick Michael Gawan (accoustic.fmg@gmail.com)
}

\begin{abstract}
Abstrak
Artikel ini meneliti perubahan dalam amalan federalisme di Malaysia dengan merujuk kepada Sarawak di bawah pentadbiran Adenan Satem (2014-2017) sebagai rujukan utama. Penelitian ini dibuat dengan membuat analisa terhadap tuntutan autonomi dan pengembalian semula hak-hak negeri Sarawak seperti yang termaktub dalam Perjanjian Malaysia 1963 (MA63). Artikel ini juga menilai respons kerajaan persekutuan terhadap perjuangan MA63 negeri Sarawak dan implikasi tindakan negeri terhadap hubungan persekutuan-negeri. Artikel ini adalah bersifat kualitatif sepenuhnya. Ia menggunakan gabungan kaedah kajian desktop, arkib dan perpustakaan secara intensif untuk mendapatkan data yang sedia ada. Temu bual mendalam juga dilaksanakan dengan individu-individu tertentu yang mempunyai pengetahuan tentang topik kajian. Dapatan penting kajian dapat dirumuskan seperti berikut: 1) impak tuntutan MA63 Sarawak di bawah Adenan adalah lebih mendalam ekoran daripada kejayaan tindakan populis beliau, prestasi elektoral beliau yang mengagumkan dan pendekatan pragmatik kepimpinan negeri di dalam menguruskan hubungan persekutuan-negeri 2) kerajaan persekutuan memilih untuk memberi respon secara progresif berbanding regresif kepada tuntutan Sarawak kerana Sarawak memiliki pengaruh untuk mengimbangi kuasa politik yang memanfaatkan kerajaan persekutuan 3) terakhir, perubahan dalam sistem federalisme Malaysia sepanjang tahun 2014-2017 memperlihatkan desentralisasi fungsi-fungsi administratif dan pemerkasaan Sarawak dalam pembuatan keputusan.
\end{abstract}

Kata kunci: autonomi, Adenan Satem, federalisme, Sarawak, pemusatan kuasa, desentralisasi

\section{Sarawak and Federalism Under the Leadership of Adenan Satem, 2014-2017}

\begin{abstract}
This article examines changes in the practice of the Malaysian federalism by using Sarawak under Adenan Satem (2014-2017) as a point of reference. By examining the changes, it analyses Sarawak's demands for autonomy and reinstatement of the rights accorded to the state based on the Malaysia Agreement 1963 (MA63). The article also assesses the responses of the federal government towards Sarawak's MA63 struggles and the implications of the state's actions to federal-state relations. The study was mainly qualitative. It used a combination of intensive library, archival and desktop research in gathering the data. In-depth interviews were also conducted with people from various backgrounds familiar with the topic. The key findings of the study are as follows: 1) the impacts of Sarawak's MA63 demands were more profound under Adenan due to his hugely successful populist actions, impressive electoral performance and the state leadership's pragmatic approach to federal-state relationships 2) the federal government chose to respond progressively rather than regressively to Sarawak's demand as the state had the political leverage in tilting the balance of power in the ruling federal government's favour 3) finally, changes in the Malaysian federalism during the period of 2014-
\end{abstract}


DOI: https://doi.org/10.47405/mjssh.v6i10.1048

2017 were characterised by the decentralisation of administrative functions and empowerment of Sarawak in making decisions.

Keywords: autonomy, Adenan Satem, federalism, Sarawak, centralisation, decentralization

\section{Pengenalan}

Malaysia menggunakan sistem federalisme semenjak mencapai kemerdekaan pada tahun 1957 sehingga kepada pembentukan Malaysia pada tahun 1963. Sistem federalisme yang berasal dari perkataan federal merujuk kepada perkataan Latin iaitu foedus yang bermaksud perjanjian rasmi (Elazar, 1987). Oleh yang demikian, Perjanjian Malaysia 1963 (MA63) yang membawa kepada pembentukan Malaysia boleh dianggap sebagai perjanjian rasmi yang dimeterai bersama oleh United Kingdom, Persekutuan Malaya, Borneo Utara (Sabah), Sarawak dan Singapura. Perjanjian ini ditandatangani di London pada 9 Julai 1963 telah didaftarkan di sekretariat Pertubuhan Bangsa-bangsa Bersatu pada 21 September 1970 oleh United Kingdom of Great Britain dan Northern Ireland dengan nombor rujukan 10760.

Malaysia merupakan antara negara yang mengamalkan sistem federalisme sebagai sistem pentadbiran negara semenjak mencapai kemerdekaan pada 31 Ogos 1957. Sejarah sistem federalisme di Malaysia dapat dilihat selepas pembentukan Persekutuan Tanah Melayu pada tahun 1948 yang bertitik tolak daripada peristiwa penentangan penduduk tempatan terhadap Malayan Union (MU) dengan menggabungkan kesemua negeri di Tanah Melayu di bawah satu sistem pentadbiran. Maka, dengan pembentukan Persekutuan Tanah Melayu, kedaulatan negeri-negeri Melayu telah dikembalikan semula selepas melalui fasa penjajahan oleh pihak British. Selain itu, pembentukan Persekutuan Tanah Melayu juga diikuti dengan penggubalan Perlembagaan Persekutuan yang menjadi asas kepada kemerdekaan Tanah Melayu pada tahun 1957.

Perlembagaan persekutuan yang digubal pada tahun 1957 memberikan banyak kuasa kepada kerajaan persekutuan. Hal ini adalah disebabkan oleh tiga faktor iaitu kerajaan persekutuan perlu membangunkan negeri dan meningkatkan taraf hidup rakyat, menangani ancaman komunis dan menjaga hubungan antara kaum (Oswald, 2017). Selepas Persekutuan Malaya berjaya dibentuk, Perdana Menteri Persekutuan Malaya Tunku Abdul Rahman mengemukakan idea untuk menubuhkan Persekutuan Malaysia pada tahun 1961 dengan hasrat untuk menggabungkan Persekutuan Malaya dengan Singapura, Brunei, Sabah dan Sarawak.

Oleh yang demikian, pada 16 September 1963, Persekutuan Malaysia ditubuhkan dengan mengekalkan sistem federalisme yang sedia ada tetapi dengan melakukan beberapa pindaan dalam perlembagaan persekutuan yang melibatkan bidang kuasa dan autonomi negeri Sabah dan Sarawak. Negeri Sabah dan Sarawak diberikan kedudukan istimewa berbanding negeri-negeri lain di dalam Persekutuan Malaysia. Kedudukan istimewa yang dimiliki oleh Sabah dan Sarawak adalah berdasarkan kepada beberapa faktor seperti perbezaan budaya dan agama, latar belakang geografi, kadar kemiskinan penduduk, dan perjanjian pembentukan Malaysia yang dibuat di peringkat antarabangsa (Faruqi, 2012). Sebelum membentuk Persekutuan Malaysia, Sabah dan Sarawak telah mengemukakan beberapa syarat untuk melindungi kepentingan negeri berkenaan.

Syarat-syarat berkenaan dikenali sebagai "18 Perkara" bagi Sarawak dan "20 Perkara" bagi Sabah yang telah diajukan kepada Jawatankuasa Antara Kerajaan (Inter-Governmental Committee atau IGC) yang diketuai oleh Lord Lansdowne ${ }^{1}$. Penubuhan Jawatankuasa Antara Kerajaan ini adalah hasil

\footnotetext{
120 Perkara diperkenalkan oleh Sabah dan 18 Perkara oleh Sarawak merupakan memorandum yang mengandungi hak-hak yang diperjuangkan oleh kedua-dua negeri tersebut. Pemimpin Sabah dan Sarawak mengemukakan memorandum ini untuk dipertimbangkan oleh Jawankuasa Antara Kerajaan sebagai syarat untuk kemasukan Sabah dan Sarawak ke dalam Persekutuan Malaysia. Jawatankuasa Antara Kerajaan pula ditubuhkan pada bulan Ogos 1962 hasil daripada cadangan Suruhanjaya Cobbold.
} 
daripada cadangan yang dikemukakan oleh Suruhanjaya Cobbold bagi membincangkan perkara yang memberikan jaminan kepada hak dan kepentingan rakyat Sabah dan Sarawak apabila menyertai Persekutuan Malaysia. Walaupun tidak semua syarat yang dikemukakan oleh Sabah dan Sarawak dimasukkan ke dalam Laporan Jawatankuasa Antara Kerajaan (Laporan IGC), namun 18 Perkara dan 20 Perkara dianggap penting kerana kedua-duanya menjadi asas kepada MA63 dan pembentukan perlembagaan persekutuan yang baharu.

Sistem federalisme yang diamalkan di Malaysia adalah berbeza jika dibandingkan dengan amalan federalisme di negara lain. Sistem federalisme di negara Eropah, misalnya, melaksanakan desentralisasi kuasa bagi meningkatkan kecekapan pihak kerajaan di peringkat tempatan. Namun begitu, dalam konteks sistem federalisme di Malaysia, berlaku pemusatan kuasa oleh kerajaan persekutuan. Amalan pemusatan kuasa di dalam sistem federalisme telah menyebabkan konflik di antara kerajaan persekutuan dengan kerajaan negeri. Konflik ini dapat dilihat menerusi beberapa peristiwa campur tangan kerajaan persekutuan dalam pentadbiran kerajaan negeri di Kelantan, Terengganu, Sabah dan Sarawak. Bagi negeri Sarawak, campur tangan kerajaan persekutuan berlaku pada tahun 1966 sehingga menyebabkan pemecatan Ketua Menteri Sarawak iaitu Stephen Kalong Ningkan yang membangkitkan isu kuasa autonomi Sarawak. Selepas penyingkiran Stephen, pemimpin Sarawak lebih cenderung untuk menggunakan kaedah yang disifatkan lebih diplomatik di dalam berhadapan dengan kerajaan persekutuan. Konflik yang berlaku di antara kerajaan persekutuan dengan kerajaan negeri adalah tidak dapat dielakkan khususnya bagi negeri yang di tadbir oleh parti pembangkang (Yusoff, 2006; Harding \& Chin, 2015).

Perlembagaan persekutuan sememangnya distrukturkan untuk memberikan lebih banyak kuasa kepada kerajaan persekutuan. Pengaruh kerajaan persekutuan diperkuatkan lagi dengan dominasi politik parti gabungan Barisan Nasional (BN) yang telah memerintah sejak Malaysia mencapai kemerdekaan pada tahun 1957. Namun begitu, kejatuhan BN pada tahun 2018 telah melemahkan pengaruh kerajaan persekutuan dan pemusatan kuasa yang diamalkannya.

Artikel ini membincangkan tentang perubahan yang dialami oleh sistem federalisme Malaysia di dalam konteks perkembangan politik Sarawak di bawah pemerintahan Adenan Satem, Ketua Menteri Sarawak, dari tahun 2014-2017. Ia menganalisis tuntutan autonomi dan pengembalian semula hak-hak negeri Sarawak seperti yang termaktub di dalam MA63 dan menilai respons kerajaan persekutuan terhadap perjuangan MA63 negeri Sarawak.

\section{Tentangan Terhadap Pemusatan Kuasa Kerajaan Persekutuan}

Pemusatan kuasa oleh kerajaan pusat jelas dalam pembahagian kuasa di antara kerajaan pusat dengan kerajaan negeri berdasarkan kepada peruntukan perlembagaan persekutuan (Yusof \& Augustino, 2011). Pemusatan kuasa ini memberikan kelebihan kepada kerajaan pusat sama ada dari segi jurisdiksi mahupun peruntukan yang telah dimaktubkan di dalam Jadual Ke-9 dan Ke-10 Perlembagaan Persekutuan. Dalam Jadual Ke-9, misalnya, kerajaan persekutuan menguasai bidang-bidang seperti hal ehwal negeri, pertahanan, keselamatan dalam negeri, kewangan, pendidikan dan kesihatan. Walaupun begitu, bidang kewangan sering kali mendapat perhatian kerana ia digunakan oleh kerajaan persekutuan untuk memberikan tekanan politik kepada kerajaan negeri yang dikuasai oleh pihak pembangkang (Yusoff, 2002).

Perbincangan seterusnya di bawah melihat secara terperinci mengenai penentangan pemusatan kuasa oleh pemimpin negeri Sabah dan Sarawak. Namun begitu, tentangan secara terbuka yang dilakukan oleh Ketua Menteri Sarawak Adenan dilihat sebagai berkesan bukan hanya di dalam mendesak kerajaan persekutuan untuk memberikan lebih banyak kuasa autonomi kepada Sarawak tetapi juga di

Jawatankuasa ini ditubuhkan bagi menjamin hak dan kepentingan rakyat Sabah dan Sarawak agar tidak tergugat apabila menyertai Malaysia. Jawatankuasa ini dipengerusikan oleh Lord Landsdowne dengan ahli jawatankuasa terdiri daripada wakil kerajaan British, Persekutuan Tanah Melayu, Borneo Utara dan Sarawak. 
dalam mengubah sistem federalisme Malaysia yang selama ini dicorakkan oleh pemusatan kuasa oleh kerajaan persekutuan.

\section{Era pemerintahan Donald Stephens di Sabah, 1963-1964}

Sewaktu era pemerintahan Ketua Menteri Sabah yang pertama, Donald Stephens, beberapa konflik telah berlaku di antara kerajaan persekutuan dengan kerajaan negeri Sabah. Stephens menganggap kerajaan persekutuan tidak komited di dalam memelihara kuasa dan autonomi negeri Sabah kerana gagal melaksanakan MA63 sepenuhnya. Selain itu, Stephens juga mahu agar pelaksanaan MA63 dilakukan dengan merujuk kepada 20 Perkara yang dibangkitkan di peringkat Jawatankuasa Antara Kerajaan. Stephens yang lantang di dalam menyuarakan isu-isu berkaitan autonomi Sabah disingkirkan daripada jawatan ketua menteri dan diberikan jawatan menteri tanpa portfolio di peringkat kerajaan persekutuan.

Hal ini dilihat sebagai satu tindakan daripada kerajaan persekutuan untuk memberikan tekanan terhadap Stephens yang membangkitkan isu kuasa dan autonomi Sabah. Laporan Jawatankuasa Antara Kerajaan mempunyai penerangan yang lebih terperinci mengenai kehendak negeri Sabah di dalam menjamin kepentingan hak negeri tersebut sebelum pembentukan Malaysia (Means, 1968). Maka, Stephens mahu agar MA63 dibacakan bersama dengan Laporan IGC agar kuasa autonomi negeri tidak dilupakan atau terhakis pada masa akan datang. Tekanan yang diberikan oleh kerajaan persekutuan juga dilihat oleh masyarakat Kadazandusun sebagai satu bentuk diskriminasi terhadap parti UPKO (United Pasok Momogun Kadazan Organisation) yang merupakan parti dominan yang mewakili masyarakat Kadazandusun.

\section{Sabah di bawah pentadbiran Parti Bersatu Sabah (PBS), 1985-1994}

Parti Bersatu Sabah (PBS) yang dipimpin oleh Joseph Pairin Kitingan berjaya menewaskan parti Berjaya (Parti Bersatu Rakyat Jelata Sabah) pimpinan Harris Salleh di dalam pilihan raya negeri Sabah tahun 1985. Parti Berjaya ditolak oleh rakyat Sabah disebabkan oleh corak pentadbirannya yang dianggap pro-persekutuan dan dasar parti tersebut yang telah menimbulkan rasa tidak puas hati masyarakat Kadazandusun (Kalimuthu, 1986). Pairin yang mewakili masyarakat Kadazandusun juga telah disingkirkan daripada kerajaan negeri sebelum Pilihan Raya Negeri Sabah pada tahun 1985. Penyingkiran ini mendorong Pairin untuk menubuhkan PBS bagi menghadapi parti Berjaya di dalam pilihan raya negeri 1985. Hasilnya, PBS berjaya memenangi pilihan raya tersebut dan Pairin dipilih sebagai Ketua Menteri Sabah ke-7 menggantikan Harris Salleh. Pada peringkat awal kemenangan PBS, beberapa siri demonstrasi yang didakwa dirancang oleh parti USNO (United Sabah National Organisation) dan Berjaya dilakukan di Sabah disamping turut berlaku beberapa insiden letupan bom di beberapa kawasan di negeri tersebut. Keadaan huru-hara yang berlaku di Sabah menyebabkan Dewan Undangan Negeri (DUN) Sabah terpaksa dibubarkan selepas 10 bulan kemenangan PBS bagi memberi laluan kepada pilihan raya mengejut untuk memulihkan keadaan politik di Sabah. Pilihan Raya Negeri Sabah yang diadakan pada tahun 1986 memperlihatkan sokongan kepada PBS semakin bertambah dengan kemenangan sebanyak 26 kerusi pada tahun 1985 kepada 34 kerusi pada tahun 1986.

Sepanjang pemerintahan PBS pada tahun 1986, Jeffrey Pairin Kitingan, adik kepada Pairin, membuat tuntutan kepada kerajaan persekutuan supaya menaikkan peratus royalti minyak negeri Sabah daripada 5\% kepada 50\%, meningkatkan pengambilan penduduk tempatan untuk bekerja di dalam bidang profesional dan juga melakukan tindakan segera bagi membendung kemasukan pendatang asing tanpa izin (PTI) ke negeri Sabah (Agus, 2001). Pada masa yang sama, PBS juga menyuarakan kepada kerajaan persekutuan supaya memberikan layanan seadilnya kepada Sabah selaku "rakan kongsi" yang telah menubuhkan Malaysia secara bersama. PBS menegaskan supaya hak-hak Sabah yang terkandung di dalam 20 Perkara dan MA63 dilaksanakan sepenuhnya oleh kerajaan persekutuan.

Tindakan PBS ini dianggap sebagai mewujudkan gerakan anti-federal terhadap kerajaan persekutuan. Sebagai tindak balas, kerajaan persekutuan mengambil beberapa tindakan regresif dengan mengenakan diskriminasi ekonomi terhadap negeri Sabah. Peruntukan daripada kerajaan persekutuan kepada 
kerajaan negeri Sabah dikurangkan, misalnya, dalam isu pembinaan perumahan untuk rakyat negeri Sabah (Yusoff, 2002). Selain itu, kerajaan persekutuan juga menganggap PBS mendiskriminasikan penduduk Sabah yang beragama Islam dengan memindahkan beberapa orang pegawai daerah dan penjawat awam yang dianggap menggugat kedudukan PBS (Yusoff, 2002). Malahan, di era pemerintahan Perdana Menteri ke-4, Mahathir Mohammad, kerajaan persekutuan bertindak lebih regresif terhadap kerajaan negeri Sabah dengan menggunakan Akta Keselamatan Dalam Negeri (ISA) untuk menangkap pemimpin PBS seperti Maximus Ongkili, Mark Koding dan Pairin sendiri. Pemimpin negeri Sabah ditangkap di bawah akta ini kerana dianggap memberikan ancaman keselamatan kepada negara disamping dikenakan tuduhan melakukan rasuah.

\section{Era Pemerintahan Stephen Kalong Ningkan di Sarawak, 1963-1966}

Pemerintahan Stephen Kalong Ningkan di Sarawak turut berhadapan dengan pemusatan kuasa oleh kerajaan persekutuan yang mencampuri urusan pentadbiran kerajaan negeri. Seperti mana kerajaan negeri Sabah yang mahu kerajaan persekutuan melaksanakan sepenuhnya MA63, Stephen juga mempunyai pendirian untuk memelihara dan menyuarakan kuasa autonomi Sarawak.

Isu pendidikan dan pengenalan bahasa kebangsaan merupakan isu utama yang menjadi titik tolak kepada konflik di antara kerajaan persekutuan dengan kerajaan negeri Sarawak pimpinan Stephen. Kerajaan negeri Sarawak berpendirian untuk tidak tergesa-gesa melaksanakan Bahasa Melayu sebagai bahasa kebangsaan di Sarawak. Bagi Stephen, pelaksanaan polisi ini tidak semestinya perlu dipercepatkan seiring dengan Laporan IGC yang menetapkan bahawa sebarang perubahan yang ingin dilakukan di negeri Sabah dan Sarawak hanya boleh dilakukan sehingga tahun 1973 dan diluluskan di peringkat Dewan Undangan Negeri. Selain itu, perubahan berkenaan juga masih dapat ditangguhkan jika kerajaan negeri belum bersedia untuk melaksanakannya (Leigh, 1974). Dalam isu penggunaan Bahasa Melayu, Stephen menyatakan bahawa majoriti kaum Iban di Sarawak menggunakan Bahasa Inggeris sebelum ini dan ia melayakkan mereka untuk membuat permohonan biasiswa pendidikan untuk belajar di luar negara. Selain itu, Stephen juga menjelaskan bahawa majoriti masyarakat kaum Dayak telah memberikan sokongan kuat terhadap pembentukan Persekutuan Malaysia dan tanpa sokongan daripada masyarakat kaum Dayak, Persekutuan Malaysia tidak akan menjadi kenyataan.

Perdana Menteri Tunku Abdul Rahman beranggapan bahawa jika kerajaan negeri Sarawak tidak bekerjasama dengan kerajaan persekutuan untuk melaksanakan dasar-dasar kebangsaan maka hubungan antara kedua-dua peringkat kerajaan akan terjejas dan akan memberikan kesan terhadap perpaduan di negara ini. Selain itu, Abdul Rahman juga beranggapan bahawa pendirian kerajaan negeri Sarawak banyak dipengaruhi oleh pegawai-pegawai British yang masih berkhidmat di Sarawak. Pertentangan di antara Abdul Rahman dan Stephen ini menyebabkan krisis politik yang mendorong kerajaan persekutuan untuk mengistiharkan darurat di negeri Sarawak pada tahun 1966.

Pengisytiharan darurat berpunca daripada kekecohan dan demonstrasi yang berlaku di Sarawak selepas mahkamah memutuskan pemecatan Stephen oleh Gabenor Sarawak sebelum ini adalah tidak sah. Apabila darurat diisytiharkan oleh kerajaan persekutuan, Gabenor Sarawak diberikan kuasa untuk memecat ketua menteri dan Stephen disingkirkan buat kali kedua sebagai ketua menteri. Justeru, dengan pemecatan Stephen, kerajaan persekutuan telah berjaya meredakan kembali hubungan dengan kerajaan negeri Sarawak. Pelantikan Tawi Sli sebagai ketua menteri bagi menggantikan Stephen berjaya memulihkan kembali hubungan kerajaan persekutuan dengan kerajaan negeri Sarawak kerana pendekatan pro kerajaan persekutuan yang diambil oleh Tawi.

\section{Normalisasi Hubungan Persekutuan-Negeri dan Perkembangan Politik Sarawak, 1970-2014}

Pelantikan Tawi Sli sebagai Ketua Menteri Sarawak pada 23 September 1966 adalah permulaan kepada penyelarasan sistem politik di Sarawak mengikut acuan Semenanjung Malaysia yang bertunjangkan kepada parti politik Melayu Islam di bawah UMNO. Sistem politik ini diperkukuhkan semasa era pemerintahan Abdul Rahman Yaakub sebagai Ketua Menteri Sarawak yang ketiga dari 
tahun 1970 sehingga 1981. Penggabungan parti PESAKA (Parti Pesaka Anak Sarawak) dengan parti BUMIPUTERA membentuk Parti Pesaka Bumiputera Bersatu (PBB) telah mengukuhkan kedudukan masyarakat Melayu/Melanau di dalam politik Sarawak. Pengenalan Dasar Ekonomi Baru (DEB) membuka ruang kepada Abdul Rahman Yaakub untuk memperkenalkan dasar tersebut untuk masyarakat Bumiputera Sarawak. Menerusi pengenalan dasar ini, beliau memberikan hak perlesenan kayu balak kepada ramai masyarakat Bumiputera termasuk di kalangan ahli keluarga beliau sendiri (Woon, 2012).

Abdul Taib Mahmud menggantikan Abdul Rahman Yaakub sebagai Ketua Menteri pada tahun 1981. Di bawah pemerintahan Taib, hubungan kerajaan negeri dengan kerajaan persekutuan adalah bersifat "reciprocal". Dengan kekuatan politik yang dimiliki oleh PBB menerusi penguasaan 2/3 majoriti parti tersebut di DUN Sarawak disamping menjadi antara penyumbang terbesar kepada jumlah kerusi yang dikuasai oleh BN di peringkat nasional, Taib diberikan kepercayaan sepenuhnya oleh kerajaan persekutuan untuk mentadbir negeri Sarawak. Malah, semasa berlakunya Peristiwa Ming Court pada tahun 1987, kerajaan persekutuan secara terbuka memberikan sokongan kepada Taib².

Dasar pentadbiran Taib menerusi pengenalan "politik pembangunan"3 banyak menyumbang kepada sokongan rakyat Sarawak khususnya sokongan daripada penduduk di luar bandar. Hal ini kerana, penduduk di luar bandar bergantung kepada pemberian projek daripada pihak kerajaan sehingga membawa kepada jalur pemikiran pembangunan di kawasan berkenaan hanya dapat dilakukan oleh kerajaan yang dipimpin oleh parti PBB.

Kestabilan politik Sarawak di bawah pentadbiran Taib diuji di dalam Pilihan Raya Negeri Sarawak pada tahun 2011. Walaupun BN Sarawak masih dapat mengekalkan majoriti 2/3 namun gabungan parti kerajaan mengalami kekalahan di beberapa kerusi DUN yang ditandingi. Parti Sarawak United People Party (SUPP), salah satu parti komponen BN, telah mengalami banyak kekalahan di kerusi DUN yang ditandingi termasuk di kerusi DUN Piasau iaitu kerusi yang ditandingi oleh pengerusi SUPP. Taib juga berhadapan dengan isu rasuah, kronisme dan nepotisme yang berlaku sepanjang era pemerintahan beliau. Isu-isu berkenaan hangat dibincangkan di media-media sosial. Disamping itu, Taib juga gagal menepati janji beliau untuk mengundurkan diri daripada jawatan selepas pilihan raya negeri pada tahun 2006. Maka, dengan isu-isu yang dikaitkan dengan Taib, Perdana Menteri pada ketika itu, Najib Razak, secara tidak langsung memberikan bantuan di dalam kempen BN Sarawak menerusi pengenalan Dasar 1Malaysia dan pengenalan Model Ekonomi Baru. Dalam masa yang sama juga, Najib turut memberikan jaminan kepada penduduk Sarawak mengenai pengunduran Taib daripada jawatan Ketua Menteri selepas pilihan raya negeri 2011. Kata Najib: "Saya cakap secara terang bahawa Taib dan saya dah ada persefahaman bahawa apa yang penting ialah peralihan secara tersusun dan teratur" (Dipetik daripada akhbar The Star bertarikh 20 Mac 2011).

Selain itu, situasi politik di peringkat nasional turut mengalami perubahan apabila BN kehilangan banyak kerusi parlimen disamping gagal membentuk kerajaan di lima buah negeri di dalam pilihan raya umum ke-12 pada tahun 2008. Kemenangan BN di 140 kerusi parlimen adalah dipengaruhi oleh kemenangan BN di Sabah dan Sarawak yang menyumbang sebanyak 54 kerusi. Sokongan daripada BN Sabah dan Sarawak membolehkan BN untuk membentuk kerajaan di peringkat nasional pada tahun 2008 dan 2013. Pengaruh negeri Sabah dan Sarawak di peringkat nasional yang semakin kuat

\footnotetext{
${ }^{2}$ Peristiwa Ming Court merujuk kepada krisis politik di Sarawak yang melibatkan Abdul Rahman Yaakub dan Abdul Taib Mahmud. Krisis politik diantara kedua-dua pemimpin tersebut menjadi serius dengan peletakkan jawatan 4 orang menteri dan 3 orang timbalan menteri di dalam kabinet Sarawak. Peletakkan jawatan ini disusuli dengan pengumuman keluar Parti Bansa Dayak Sarawak (PBDS) daripada BN Sarawak. Presiden PBDS, Leo Moggie, menuntut supaya Abdul Taib Mahmud meletakkan jawatan selaku Ketua Menteri Sarawak atau akan berhadapan dengan usul tidak percaya di dalam DUN Sarawak. Krisis tersebut berlanjutan sehingga pengumuman pilihanraya negeri oleh Taib pada tahun 1987 yang dimenangi oleh beliau dan penyokongnya.

${ }^{3}$ Istilah politik pembangunan diperkenalkan oleh Ketua Menteri Sarawak ke-4, Abdul Taib Mahmud. Istilah ini digunakan oleh Abdul Taib Mahmud untuk menggambarkan usaha yang dilakukan oleh kerajaan negeri Sarawak di dalam membangunkan negeri tersebut. Konsep ini menjelaskan bahawa pembangunan di Sarawak hanya akan dapat diteruskan dan dilestarikan dengan sokongan yang diberikan kepada BN Sarawak sebagai parti yang membentuk kerajaan.
} 
digunakan sepenuhnya oleh pemimpin-pemimpin negeri untuk menyuarakan isu-isu yang berkaitan dengan MA63.

Bagi negeri Sarawak, isu kuasa dan autonomi tidak pernah dibangkitkan selepas era pemerintahan Stephen Kalong Ningkan. Tumpuan kerajaan negeri Sarawak selepas era tersebut adalah untuk membangunkan Sarawak setanding dengan pembangunan yang ada di negeri Semenanjung Malaysia menerusi agenda politik pembangunan Taib.

\section{Kebangkitan dan Perjuangan Politik Adenan Satem, 2014-2017}

Adenan Satem dilantik menjadi Ketua Menteri Sarawak pada 28 Februari 2014 selepas peletakan jawatan Taib. Adenan menggalas tanggungjawab yang besar bagi meneruskan agenda pembangunan di Sarawak yang telah dilaksanakan oleh Taib menerusi agenda politik pembangunan Oleh yang demikian, penting bagi Adenan untuk menampilkan gaya kepimpinan politik yang berbeza daripada Taib bagi mengelakkan corak pentadbiran beliau dibayangi oleh kepimpinan Taib.

Adenan merupakan ahli politik Sarawak yang mempunyai pengalaman luas di dalam bidang pentadbiran di peringkat persekutuan dan negeri. Di peringkat persekutuan, Adenan pernah menjawat portfolio Menteri Sumber Asli dan Tenaga. Sebelum pengunduran Taib, Adenan tewas kepada Abang Johari dalam pemilihan jawatan timbalan presiden PBB. Pada ketika itu, Adenan dianggap sebagai individu yang digemari oleh Taib untuk menyandang jawatan selaku timbalan presiden PBB. Namun kekalahan Adenan dalam pemilihan jawatan berkenaan menyebabkan beliau dilantik menyandang jawatan naib presiden PBB dan kemudian dilantik sebagai ketua penerangan PBB.

Pelantikan Adenan sebagai Ketua Menteri Sarawak pada tahun 2014 tidak mengejutkan dan sudah dijangka oleh ramai individu. Walaupun dari segi hierarki jawatan di dalam PBB, Abang Johari dianggap paling kanan dan sepatutnya menjawat jawatan ketua menteri. Selain itu, pelantikan Adenan sebagai ketua menteri sekali gus meletakkan tanggungjawab kepada beliau untuk memimpin parti PBB dan BN Sarawak menghadapi pilihan raya negeri pada tahun 2016. Adenan diakui oleh ramai pihak sebagai ahli politik veteran Sarawak yang berpengalaman luas dalam pentadbiran kerajaan negeri mahupun kerajaan pusat.

Selain itu, pengunduran Taib telah menyebabkan PBB mempunyai tiga orang calon untuk dikemukakan untuk menjawat jawatan Ketua Menteri Sarawak. Calon ketua menteri terdiri daripada Adenan sendiri, Abang Johari dan Awang Tengah Ali Hassan. Daripada ketiga-tiga calon yang dikemukakan, Taib lebih cenderung untuk memilih Adenan disebabkan oleh beberapa faktor. Selain itu juga, Taib juga mempunyai kecenderungan untuk memilih Adenan sebagai balasan terhadap 'persahabatan' yang telah terjalin selama beberapa tahun disamping kesetiaan yang telah ditunjukkan oleh Adenan terhadap kepimpinan Taib sepanjang karier politik Taib. Justeru, di akhir pemilihan calon, Adenan telah dilantik untuk menerajui kepimpinan parti PBB dan seterusnya mengetuai kerajaan negeri. Hubungan erat di antara Taib dengan Adenan mempengaruhi pelantikan Adenan sebagai ketua menteri. Adenan mengetahui bahawa beliau perlu menggunakan pendekatan baharu bagi meningkatkan keyakinan rakyat terhadap BN. Adenan bukan sahaja berjaya mengetepikan pengaruh Taib dalam pentadbiran beliau, beliau juga menggunakan sepenuhnya isu MA63 bagi meningkatkan sokongan masyarakat Sarawak kepada beliau menjelang Pilihanraya Negeri Sarawak pada tahun 2016.

\section{Tuntutan Adenan Terhadap Kerajaan Persekutuan}

Adenan tidak menunggu lama untuk bertindak bagi merealisasikan beberapa polisi yang dilihat sebagai populis dan pro Sarawak. Beliau mengarahkan supaya perkataan 'lain-lain' sebagai salah satu kategori bangsa di dalam borang rasmi kerajaan dihapuskan. Beliau juga turut memberikan peruntukan khas kepada sekolah-sekolah Cina dan mengiktiraf pemegang sijil UEC (Unified Examination Certificate). Tindakan seterusnya yang diambil oleh Adenan ialah menurunkan tarif bil elektrik dan mengiktiraf Bahasa Inggeris sebagai bahasa rasmi di Sarawak seiring dengan Bahasa Melayu. 
Adenan juga memperkenalkan "53 Prinsip" yang menjadi manifesto kerajaan negeri ${ }^{4}$. Perkara berkaitan kuasa dan autonomi negeri Sarawak telah lama tidak dibangkitkan oleh pemimpin Sarawak selepas kerajaan persekutuan menggunakan pengisytiharan darurat di Sarawak disamping turut menggunakan Akta ISA untuk menangkap beberapa orang pemimpin yang dianggap anti-federal seperti yang berlaku di Sabah.

Bagi Adenan, kuasa dan autonomi negeri Sarawak perlu dikembalikan semula selaras dengan MA63 dan merujuk kepada Laporan IGC. Bagi Adenan, kuasa dan autonomi yang diberikan kepada kerajaan Sarawak akan membantu mempercepatkan proses pembangunan negeri Sarawak. Walaupun Sarawak mempunyai hubungan yang baik dengan kerajaan persekutuan sebelum ini, namun Sarawak masih berhadapan dengan pelbagai isu yang melibatkan kemudahan asas bagi penduduk di kawasan luar bandar dan pedalaman.

Oleh yang demikian, Adenan telah mengemukakan tuntutan kuasa dan autonomi negeri Sarawak yang dibahagikan kepada tiga fasa rundingan. Rundingan fasa pertama adalah melibatkan penurunan kuasa kerajaan negeri Sarawak dengan kerajaan persekutuan. Penurunan kuasa yang diminta oleh negeri Sarawak merangkumi kuasa yang menyentuh mengenai hal-hal pentadbiran. Seterusnya, rundingan fasa kedua melibatkan hak negeri Sarawak berpandukan kepada MA63. Bagi hak negeri Sarawak, rundingan memfokuskan kepada pencerobohan persekutuan terhadap kuasa negeri. Bagi rundingan fasa ketiga, rundingan dilakukan dengan melibatkan hal permohonan royalti minyak dan gas negeri.

Negeri Sarawak membuat tuntutan supaya royalti minyak negeri Sarawak dinaikkan daripada 5\% kepada 20\%. Adenan melihat kepentingan menaikkan peratus royalti minyak kepada Sarawak untuk merapatkan jurang miskin di antara negeri di Semenanjung dengan negeri Sarawak disamping dapat digunakan untuk melaksanakan lebih banyak pembangunan di negeri ini (Mersat, 2017). Adenan juga menyuarakan hasrat untuk membatalkan permit kerja bukan tempatan kepada syarikat Petronas. Hal ini kerana, Adenan mahu lebih ramai anak Sarawak diambil untuk bekerja dengan Petronas yang beroperasi di negeri Sarawak. Langkah agresif Adenan di dalam memberikan tekanan kepada Petronas ini disusuli dengan pengumuman moratorium kerajaan negeri bagi permohonan permit baharu untuk kakitangan Petronas dari luar Sarawak pada bulan Ogos 2016.

Adenan juga menuntut supaya 22 Julai diumumkan sebagai cuti umum di negeri Sarawak. Tarikh 22 Julai merupakan tarikh kemerdekaan negeri Sarawak daripada penjajahan British. Adenan juga menuntut supaya $90 \%$ guru yang mengajar di negeri ini mesti berasal dari negeri Sarawak. Hal ini kerana guru yang bukan berasal dari negeri Sarawak berpotensi untuk berpindah keluar semula dari Sarawak selepas beberapa tempoh. Bagi memastikan pelarasan pentadbiran di antara agensi kerajaan negeri dan persekutuan, Adenan telah mengemukakan permohonan untuk menurunkan kuasa kepada kerajaan negeri di dalam 13 bidang seperti berikut:

i. Pegawai Undang-undang Negeri diberi tauliah oleh Pendakwa Raya mengikut Kanun Tatacara Jenayah untuk membuat pendakwaan bagi kesalahan mengikut Ordinan Negeri daripada peringkat seseorang itu dikenakan pertuduhan di mahkamah rendah, hinggalah ke peringkat rayuan.

ii. Penurunan kuasa dibuat kepada pegawai negeri untuk mewakili Suruhanjaya Perkhidmatan Awam dan Suruhanjaya Perkhidmatan Pelajaran di dalam pelantikan pegawai ke dalam Perkhidmatan Awam Persekutuan, termasuk perkhidmatan perguruan dan perubatan.

iii. Jawatan di dalam Jabatan Imigresen Sarawak juga diperkemas bagi menambah baik fungsi penguatkuasaan di negeri ini melalui penambahan 100 jawatan baharu, dengan pengisian sepenuhnya dibuat menjelang akhir Februari 2016.

iv. Nisbah guru kelahiran Sarawak yang berkhidmat di negeri ini juga dinaikkan kepada 90 peratus daripada keseluruhan jumlah guru di Sarawak menjelang 2018, dan untuk

\footnotetext{
${ }^{4} 53$ Prinsip merangkumi perkara berkaitan dengan pemansuhan dan pengurangan caj, janji kerajaan kepada sekolah Cina, komitmen Petronas, transformasi luar bandar, tiada parti luar Sarawak, lebih autonomi dan penurunan kuasa Sarawak, dasar pentadbiran baharu, penggunaan Bahasa Inggeris, alam sekitar, penguatkuasaan dan pengurusan hutan, Sarawak harmoni, pendidikan teknikal, lebuh raya Pan Borneo, guru Sarawak dan tanah Sarawak.
} 
Malaysian Journal of Social Sciences and Humanities (MJSSH), Volume 6, Issue 10, (page 1 - 14), 2021

DOI: https://doi.org/10.47405/mjssh.v6i10.1048

memastikan sasaran ini tercapai, guru sementara dari pasaran terbuka dipertimbangkan dari semasa ke semasa dan mereka ini mendapat diploma pendidikan semasa tempoh mengajar.

v. Kuasa warden trafik bagi Pihak Berkuasa Tempatan Sarawak diberi kepada Majlis Bandaraya Miri, selain Dewan Bandaraya Kuching Utara dan Majlis Bandaraya Kuching Selatan.

vi. Kerajaan persekutuan juga bersetuju untuk berunding dengan kerajaan negeri sebelum sesuatu permohonan permit perikanan laut dalam dikemukakan kepada Jawatankuasa Penilaian Permit Perikanan Laut Dalam untuk dipertimbangkan.

vii. Rundingan perlu dibuat dengan kerajaan negeri di dalam merangka undang-undang persekutuan yang mempunyai kaitan atau memberi kesan terhadap Sarawak seperti yang diperuntukkan oleh undang-undang.

viii. Kerajaan persekutuan juga bersetuju untuk memberi keutamaan kepada Rancangan Pembangunan Lima Tahun Negeri Sarawak berdasarkan kelulusan bajet. Di dalam pelaksanaan projek persekutuan di Sarawak, kerajaan persekutuan bersetuju untuk berunding dengan kerajaan negeri terlebih dahulu terutamanya di dalam aspek menentukan lokasi sekolah, hospital dan pelaksanaan projek pembangunan lain.

ix. Kementerian mengambil langkah perlu untuk meningkatkan jumlah kemasukan pelajar daripada kalangan rakyat Sarawak bagi Program Ijazah Perubatan. Rakyat Sarawak akan diberi lebih banyak peluang untuk mengikuti program pengajian asasi di Universiti Malaysia Sarawak (UNIMAS).

x. Bidang berkaitan yang boleh diperturunkan kuasa dikenal pasti untuk diperturunkan kuasa ketua pengarah mengikut Seksyen 49 Akta Kualiti Alam Sekitar 1974 kepada pegawai dan jabatan negeri.

xi. Pembangunan projek perumahan di Sarawak juga akan dilaksanakan semula melalui Mesyuarat Jawatankuasa Bersama bagi memastikan agensi negeri dilibatkan sepenuhnya di dalam aspek perancangan, pelaksanaan dan pemantauan projek berkenaan di Sarawak.

xii. Pembangunan sukan di Sarawak juga akan diuruskan secara bersama dengan kerajaan negeri. Kementerian Belia dan Sukan kini di dalam proses memperkemaskan Akta Pembangunan Sukan 1997, yang dijangka selesai menjelang akhir 2016.

xiii. Kerajaan negeri melaksanakan semua fungsi di bawah Jabatan Kebajikan Masyarakat. Semua jawatan akan dipindahkan kepada Perkhidmatan Awam Negeri. Kerajaan Persekutuan akan menyumbang 50 peratus daripada kos yang terlibat seperti yang diputuskan Majlis Kewangan Negara.

Tuntutan negeri Sarawak yang melibatkan 13 Perkara ini telah dipersetujui oleh kerajaan persekutuan pada bulan Januari 2016.

\section{Populariti Adenan dan Pilihan Raya Negeri Sarawak 2016}

Populariti yang dimiliki oleh Adenan banyak dibantu oleh dasar yang diperkenalkan oleh beliau selepas memegang jawatan sebagai ketua menteri khususnya yang berkaitan dengan tuntutan kuasa dan autonomi negeri Sarawak. Berdasarkan kepada tinjauan yang dilakukan pada bulan Januari 2016, populariti Adenan di kalangan pengundi mencecah $81 \%$ berbanding 74\% pada tahun 2015 (Dipetik daripada akhbar The Star, 19 April 2016).

Populariti yang dimiliki oleh Adenan juga banyak membantu kempen BN Sarawak dalam pilihan raya negeri tahun 2016. Kempen BN Sarawak banyak menonjolkan imej Adenan sebagai individu yang menjuarai perjuangan berkenaan tuntutan kuasa dan autonomi negeri Sarawak. Selain itu, kempen BN Sarawak turut menggunakan slogan 'Adenan Fever' dan 'Team Adenan' bagi menunjukkan kekuatan yang dimiliki oleh Adenan disamping turut menunjukkan bahawa sokongan kepada mana-mana calon BN adalah sama dengan memberikan sokongan kepada Adenan untuk meneruskan agenda tuntutan kuasa dan autonomi negeri Sarawak.

Justeru, kemenangan BN Sarawak dalam Pilihan Raya Negeri Sarawak dengan memenangi 72 daripada 82 kerusi yang dipertandingkan menunjukkan impak Adenan di dalam mengembalikan 
DOI: https://doi.org/10.47405/mjssh.v6i10.1048

sokongan rakyat terhadap BN Sarawak. Dalam pilihan raya negeri tahun 2011, BN Sarawak kehilangan banyak kerusi DUN khususnya di kerusi DUN majoriti kaum Cina yang dimenangi oleh parti DAP. Namun, Dalam pilihan raya negeri tahun 2016, kerusi-kerusi DUN yang dimenangi oleh DAP berjaya dirampas kembali oleh BN seperti kerusi DUN Batu Kawa dan Piasau. Selain itu, kemenangan BN Sarawak juga menunjukkan rakyat memberikan kepercayaan kepada BN yang dipimpin oleh Adenan dalam usaha untuk mengembalikan dan memartabatkan MA63. Walaupun tindakan yang dilakukan oleh Adenan dilihat sebagai langkah populis untuk mendapatkan sokongan politik, ia bukan hanya berkesan di dalam mendesak kerajaan persekutuan untuk memenuhi tuntutan negeri Sarawak tetapi juga membantu di dalam memberikan kemenangan yang agak memberangsangkan kepada BN pada Pilihan Raya Negeri Sarawak pada tahun 2016.

Jadual 1: Perbezaan Jumlah Kerusi Yang Dimenangi Berdasarkan Parti (Pilihan Raya Negeri Sarawak 2011 dan 2016)

\begin{tabular}{lccc}
\hline \multirow{2}{*}{ Parti Bertanding } & \multicolumn{2}{c}{ Jumlah Kerusi Yang Dimenangi } & \\
\cline { 2 - 3 } & $\begin{array}{c}\text { (Pilihan Raya Negeri) } \\
\text { PRN 2011 }\end{array}$ & $\begin{array}{c}\text { (Pilihan Raya Negeri) } \\
\text { PRN 2016 }\end{array}$ & \\
\hline Barisan Nasional & & & \\
Sarawak & 35 & 40 & +4 \\
$\quad$ PBB & 6 & 7 & +1 \\
SUPP & 8 & 11 & +3 \\
PRS & 6 & 3 & -2 \\
SPDP & - & 11 & 11 \\
Calon Langsung & & & \\
Pakatan & 12 & 7 & -5 \\
Rakyat/Harapan & 3 & 3 & 3 \\
DAP & 0 & - & - \\
PKR & 0 & 0 & - \\
SNAP & 0 & - & - \\
PAS & - & 0 & - \\
PCM & - & 0 & - \\
PAN & - & 0 & - \\
STAR & 1 & 0 & 0 \\
PBDSB & & & \\
Bebas & & & \\
\hline
\end{tabular}

Nota: Parti Bumiputera Bersatu (PBB), Sarawak United People Party (SUPP), Parti Rakyat Sarawak (PRS), Sarawak Progressive Democratic Party (SPDP), Democratic Action Party (DAP), Parti Keadilan Rakyat (PKR), Sarawak National Party (SNAP), Parti Islam Se-Malaysia (PAS), Parti Cinta Malaysia (PCM), Parti Amanah Negara (PAN), State Reform Party (STAR), Parti Bansa Dayak Sarawak Baru (PBDSB)

Sumber: Suruhanjaya Pilihan Raya Malaysia (2021)

Berdasarkan kepada Jadual 1, dapat diperhatikan bahawa BN Sarawak berjaya menambahkan jumlah kemenangan kerusi DUN yang ditandingi pada tahun 2016 daripada 55 kerusi DUN kepada 72 kerusi DUN. Bagi parti pembangkang pula, kemenangan kerusi DUN semakin berkurangan daripada menang di 15 kerusi DUN kepada hanya menang 10 kerusi DUN dalam PRN 2016. Selain itu, dalam PRN Sarawak 2016, terdapat penambahan sebanyak 11 kerusi DUN baharu melibatkan Batu Kitang, Stakan, Serembu, Bukit Semuja, Gedong, Kabong, Tellian, Bukit Goram, Murum, Samalaju dan Long Lama.

Pada PRN 2016, BN Sarawak juga telah mengemukakan 13 orang calon langsung yang merujuk kepada calon boleh menang bagi mewakili BN. Penggunaan strategi calon langsung ini juga bertujuan untuk menyelesaikan isu perebutan kerusi antara parti komponen. Oleh itu, berdasarkan kepada keputusan PRN Sarawak 2016, PBB berjaya memenangi di kesemua kerusi DUN yang ditandingi termasuk menang di kerusi DUN yang baru diperkenalkan. SUPP pula berjaya menambah penguasaan 
kerusi DUN selepas memenangi 7 kerusi DUN. Kemenangan SUPP ini juga melibatkan beberapa buah kerusi panas DUN yang mana dikuasai oleh parti DAP sebelum ini. SUPP berjaya merampas kembali kerusi DUN di Batu Kawah dan Piasau menerusi calon SUPP Dr Sim Kui Hian dan Dr Sebastian Ting. Selain itu, parti PRS juga berjaya menambah bilangan kerusi DUN sebanyak 3 kerusi DUN. Pertambahan jumlah bilangan kerusi oleh SUPP turut dipengaruhi oleh kemenangan PRS di DUN Murum dan DUN Samalaju. Manakala, SPDP pula menunjukkan pengurangan penguasaan kerusi DUN yang tewas di DUN Krian dan Ba'kelalan.

Bagi parti pembangkang, keputusan PRN 2016 menunjukkan pengurangan penguasaan kerusi DUN. Pengurangan ini jelas apabila parti DAP hanya menang di 7 kerusi DUN iaitu Padungan, Pending, Kota Sentosa, Bukit Assek, Pelawan, Tanjung Batu dan Pujut. Kerusi DUN yang dimenangi dalam pilihan raya yang lepas berjaya dimenangi semula oleh SUPP seperti kerusi DUN Batu Kawah dan Piasau. Bagi parti PKR pula, parti ini masih dapat mempertahankan kerusi DUN yang dimenangi dalam PRN lalu iaitu di Batu Lintang, Krian dan Ba'kelalan. Manakala, parti komponen lain dalam PH masih belum dapat menyumbangkan kemenangan kerusi di tempat yang ditandingi.

Justeru, kemenangan BN Sarawak dan peningkatan jumlah kerusi yang dimenangi adalah petunjuk kepada kejayaan kempen yang dilakukan oleh BN. BN Sarawak dalam kempen PRN 2016 menonjolkan imej Adenan selaku pemimpin yang dapat memperjuangkan agenda menuntut kuasa dan autonomi negeri Sarawak. Hal ini juga menunjukkan bahawa rakyat Sarawak memberikan kepercayaan dan harapan kepada kerajaan negeri dan kerajaan persekutuan agar dapat menjayakan usaha tuntutan autonomi yang dilakukan oleh Adenan. Namun begitu, kemenangan besar BN Sarawak di dalam PRN 2016 juga memberikan impak terhadap perkembangan federalisme di Malaysia kerana ia mengukuhkan kedudukan politik negeri yang digunakan oleh pemimpin tempatan untuk mencabar dominasi dan pemusatan kuasa kerajaan persekutuan.

\section{Respons Kerajaan Persekutuan}

Isu kuasa dan autonomi negeri Sarawak merupakan isu yang sensitif untuk dibincangkan bersama dengan kerajaan persekutuan semasa peringkat awal pembentukan Malaysia. Hal ini disebabkan oleh wujudnya perbezaan pandangan oleh pemimpin pada ketika itu mengenai kedudukan istimewa negeri Sabah dan Sarawak di dalam Persekutuan. Selain itu, prinsip 'centralism' dan 'strong executive' semasa pemerintahan oleh Mahathir menyebabkan pemusatan kuasa oleh kerajaan persekutuan menjadi semakin meluas. Oleh itu, dalam isu tuntutan kuasa dan autonomi oleh Adenan, kerajaan persekutuan menunjukkan respon berbeza berbanding sebelum ini.

Kerajaan persekutuan memberikan respons yang positif terhadap tuntutan kuasa dan autonomi negeri Sarawak. Di bawah pentadbiran Perdana Menteri Najib Razak, kerajaan persekutuan telah memberikan beberapa desentralisasi kuasa kepada kerajaan negeri Sarawak khasnya perkara yang melibatkan kuasa pentadbiran. Desentralisasi kuasa pentadbiran oleh kerajaan persekutuan memberikan kuasa kepada Sarawak untuk mengambil lebih ramai rakyat negeri Sarawak untuk bekerja di jabatan persekutuan, operasi Petronas di Sarawak dan memperkasakan pegawai perundangan negeri termasuk pelaksanaan Projek Lebuh Raya Pan Borneo.

Selain itu, kerajaan persekutuan juga memberikan jaminan untuk mengembalikan semula hak negeri Sarawak yang telah terhakis. Najib memberikan jaminan dengan menyatakan 'hak-hak Sarawak yang telah diambil alih oleh kerajaan persekutuan semasa pelaksanaan Perjanjian Malaysia, kami bersedia mempertimbangkan untuk mengembalikan kepada Sarawak' (Dipetik daripada Astro Awani bertarikh 10 Februari 2017).

Selain itu, Jawatankuasa Teknikal berkaitan penurunan kuasa kepada Sarawak ditubuhkan pada tahun 2016 bagi memastikan tuntutan oleh negeri Sarawak dapat dilaksanakan. Jawatankuasa teknikal ini berfungsi untuk mengenal pasti isu kegagalan pematuhan kuasa dan autonomi negeri Sarawak dalam konteks Laporan Jawatankuasa Antara Kerajaan. Selain itu juga, jawatankuasa teknikal ini juga akan meneliti semula Perjanjian Malaysia 1963, Akta Malaysia 1963 dan laporan bertulis yang lain bagi 
mengenal pasti kegagalan pematuhan oleh kerajaan persekutuan. Jawatankuasa teknikal ini dipengerusikan bersama oleh Menteri di Jabatan Perdana Menteri, Nancy Shukri selaku wakil negeri Sarawak dan Menteri Luar, Anifah Aman yang mewakili negeri Sabah. Menerusi mandat yang diberikan oleh rakyat kepada BN Sarawak dalam pilihan raya negeri 2016, Adenan mempunyai political leverage yang besar bagi menggesa kerajaan persekutuan untuk mempercepatkan proses penurunan kuasa kepada Sarawak.

Respons yang positif dan responsif oleh kerajaan persekutuan dalam isu tuntutan kuasa dan autonomi negeri Sarawak menunjukkan perubahan dan dinamika politik di Malaysia dalam konteks sistem federalisme. Walaupun sistem federalisme di Malaysia masih mempunyai ciri-ciri pemusatan kuasa oleh kerajaan persekutuan, tetapi proses desentralisasi kuasa berjaya dilakukan ke atas negeri Sarawak tanpa tekanan politik ke atas negeri Sarawak seperti yang berlaku pada tahun 1966. Proses desentralisasi kuasa yang berlaku ke atas negeri Sarawak juga menunjukkan perubahan terhadap sistem federalisme di Malaysia yang membenarkan negeri Sarawak melaksanakan autonomi tersendiri seiring dengan fungsi dan sistem federalisme itu sendiri.

\section{Kesan Kepada Sistem Federalisme Malaysia}

Tuntutan kuasa dan autonomi yang dilakukan oleh negeri Sarawak di bawah pimpinan Adenan memberikan impak terhadap perkembangan sistem federalisme di Malaysia. Sistem federalisme di Malaysia yang mempunyai kadar pemusatan kuasa yang tinggi telah tercabar ekoran tuntutan kuasa dan autonomi negeri Sarawak. Perkembangan yang berlaku dalam sistem federalisme di Malaysia adalah selari dengan konsep asimetri yang membenarkan wilayah dalam persekutuan mengekalkan autonomi masing-masing (Tarlton, 1965). Dalam konteks sistem federalisme di Malaysia, pemusatan kuasa oleh kerajaan persekutuan dapat dileraikan menerusi desentralisasi kuasa oleh kerajaan persekutuan. Melalui desentralisasi kuasa, kerajaan Sarawak mengharapkan agar ia dapat menguruskan pelantikan penjawat awam dalam sektor pendidikan dan perubatan dan seterusnya meningkatkan kecekapan kerajaan yang selama ini dihambat oleh masalah birokrasi dalam proses pembuatan keputusan di kedua-dua peringkat kerajaan.

Selain itu, proses desentralisasi kuasa yang diberikan kepada negeri Sarawak adalah manifestasi kepada hasrat dan tujuan MA63 yang dimeterai sebelum pembentukan Persekutuan Malaysia. Bagi Adenan, desakan yang dilakukan oleh negeri Sarawak adalah selaras dengan MA63. Walaupun tindakan Adenan ini dilihat sebagai terlalu pro-Sarawak dan bersifat populis, ia berjaya meningkatkan populariti beliau dan BN kerana langkah sebegini tidak pernah dilakukan oleh pemimpin Sarawak sebelum ini. Selain itu, Adenan juga menggunakan political leverage dan kedudukan negeri Sarawak yang dianggap sebagai 'deposit tetap ${ }^{5}$ ' BN untuk melaksanakan kuasa dan autonomi seperti yang telah dilakukan oleh Stephen Kalong Ningkan dahulu. Bagi sesetengah pihak, tuntutan yang dimulakan oleh Adenan adalah betul dan sesuai dengan dinamika yang sedang berlaku dalam politik tanah air.

Walau bagaimanapun, proses desentralisasi kuasa yang dilakukan ke atas negeri Sarawak tidak mungkin dapat dilaksanakan di negeri-negeri Semenanjung Malaysia. Hal ini kerana, pembentukan Persekutuan Tanah Melayu pada tahun 1948 tidak memberikan kuasa dan autonomi tertentu kepada negeri-negeri di Semenanjung Malaysia. Berdasarkan kepada Perlembagaan Persekutuan, kuasa kerajaan negeri hanya dibatasi dengan bidang kuasa yang telah dinyatakan di dalam Jadual Ke-9 Perlembagaan Persekutuan. Situasi ini berbeza di Sabah dan Sarawak kerana kuasa dan autonomi negeri dibincangkan dan didokumentasikan di dalam MA63 dan di dalam Laporan IGC sebelum Persekutuan Malaysia dibentuk. Beberapa peruntukan tambahan juga diberikan kepada negeri Sabah dan Sarawak. Kuasa dan autonomi yang dimiliki oleh negeri Sabah dan Sarawak menjadi asas kepada kedudukan istimewa yang dimiliki oleh negeri ini disamping menjadi "rakan setara" di dalam Persekutuan seperti yang terdapat dalam Perkara 1(2) (b) sebelum ia dipinda pada tahun 1976.

\footnotetext{
${ }^{5}$ Sabah dan Sarawak dianggap sebagai 'deposit tetap' kerana sokongan kuat yang diberikan oleh keduadua negeri tersebut kepada BN di peringkat nasional. Malah, jumlah kerusi yang dimenangi oleh BN Sarawak dan Sabah pada tahun 2008 dan 2013, membolehkan BN di peringkat persekutuan menubuhkan kerajaan.
} 
Namun begitu, proses desentralisasi kuasa yang dilakukan di Sarawak perlu disusuli dengan penyusunan semula sistem federalisme di Malaysia bagi mengelakkan pertindihan kuasa di antara kerajaan persekutuan dan kerajaan negeri disamping mengurangkan pemusatan kuasa kerajaan pusat. Ini juga bermakna bahawa kerajaan persekutuan perlu bertindak dalam konteks kebertanggungjawaban sesebuah kerajaan ke atas kerajaan negeri tanpa dibatasi oleh perbezaan fahaman politik. Maka, dengan memperbaiki amalan dalam sistem federalisme di Malaysia, sistem ini akan dapat mewujudkan sebuah kerajaan persekutuan yang responsif terhadap keperluan kerajaan negeri tanpa mengira perbezaan parti politik yang memerintah disamping mengetepikan soal sama ada negeri berkenaan mempunyai autonomi atau tidak.

Oleh itu, tuntutan kuasa dan autonomi oleh negeri Sarawak akan memberikan banyak manfaat kepada negeri Sabah dan Sarawak pada masa akan datang. Keupayaan kerajaan negeri untuk mendapatkan sumber peruntukan bagi tujuan pembangunan akan dapat diperolehi berdasarkan kepada desentralisasi kuasa yang dijalankan. Selain itu, agenda tuntutan kuasa dan autonomi negeri Sarawak harus diteruskan oleh kerajaan negeri Sarawak selepas ketiadaan Adenan. Walaupun berlaku perubahan kerajaan pada tahun 2018, rundingan oleh negeri Sarawak tetap dilaksanakan oleh kepimpinan baharu negeri yang diwakili oleh Abang Johari. Rundingan yang dilakukan di antara kedua-dua peringkat kerajaan akan menguji sejauh mana perubahan yang berlaku dalam sistem federalisme di Malaysia akan berpihak kepada negeri Sabah dan Sarawak.

\section{Kesimpulan}

Tuntutan kuasa dan autonomi negeri Sabah dan Sarawak dijangka akan berterusan dan akan terus menguji sistem federalisme Malaysia. Tindakan Adenan melalui tuntutan autonomi negeri Sarawak telah berjaya mendesak kerajaan persekutuan untuk memberikan kuasa-kuasa tertentu kepada kerajaan negeri Sarawak. Tindakan Adenan dan respons daripada kerajaan persekutuan perlu dilihat dalam konteks semasa politik pada tahun 2014-2016. Pertama, kerajaan persekutuan di bawah pemerintahan BN memerlukan sokongan politik daripada kerajaan Sarawak di bawah BN Sarawak. Situasi ini digunakan sepenuhnya oleh Adenan untuk menuntut hak-hak negeri Sarawak seperti yang termaktub di dalam MA63 dan perlembagaan persekutuan. Kedua, Adenan menggunakan sepenuhnya mandat besar yang diberikan kepada BN Sarawak pada tahun 2016 untuk meneruskan tuntutan autonomi negeri Sarawak walaupun ia dilihat sebagai terlalu pro-Sarawak. Ketiga, tindakan Adenan dan respons daripada kerajaan persekutuan telah membuka peluang kepada penyusunan semula kuasa pentadbiran negeri dan persekutuan.

Usaha untuk mengembalikan semula kuasa dan autonomi negeri Sarawak diteruskan oleh GPS (Gabungan Parti Sarawak) di bawah pimpinan Abang Johari yang menggantikan Adenan sebagai Ketua Menteri pada tahun $2017^{6}$. Usaha kerajaan pimpinan GPS yang dilihat sebagai satu kesinambungan daripada dasar yang diperkenalkan oleh Adenan memperlihatkan beberapa keputusan telah berjaya dicapai di antara kerajaan negeri dan kerajaan pusat seperti penurunan kuasa kepada kerajaan negeri di dalam mengurus aktiviti-aktiviti perlombongan, minyak, dan gas, dan pemberian pendapatan yang lebih besar kepada kerajaan negeri daripada industri minyak dan gas yang diusahakan di peringkat negeri.

Selain itu, usaha juga sedang dilakukan oleh kerajaan pimpinan GPS dan kerajaan persekutuan untuk meminda perlembagaan persekutuan yang melibatkan Artikel 1 (2), Artikel 160 (2), dan Artikel 95B. Adakah tindakan Adenan yang terdahulu yang disusuli oleh usaha kerajaan pimpinan GPS pada ketika ini akan membawa perubahan yang lebih besar atau bersifat piecemeal dan cosmetic terhadap sistem federalisme Malaysia? Apa yang pasti, sistem federalisme yang selama ini didominasi oleh kerajaan persekutuan dan perlembagaan persekutuan yang dianggap sebagai federal-centric tidak akan sama lagi seiring dengan perubahan politik Malaysia setelah kejatuhan BN pada tahun 2018.

\footnotetext{
${ }^{6}$ GPS (Gabungan Parti Sarawak) melibatkan komponen PBB, PRS, SUPP dan PDP. Selepas BN tewas di dalam pilihan raya umum pada tahun 2018, parti-parti komponen BN Sarawak mengumumkan untuk keluar dan menubuhkan GPS.
} 


\section{Rujukan}

Abdullah, M.N. (1979). Kemasukan Sabah dan Sarawak ke dalam Persekutuan Malaysia. Dewan Bahasa dan Pustaka.

Adam, R. (2009). Biografi Politik Tunku Abdul Rahman Putra. Dewan Bahasa dan Pustaka.

Chin, J. (2004). Sabah and Sarawak: The More Things Change The More They Remain The Same. Southeast Asian Affairs, 156-168.

Chin, J. (2019). The 1963 Malaysia Agreement (MA63): Sabah and Sarawak and the Politics of Historical Grievances. In S. Lemiere (Ed.), Minorities Matter: Malaysian Politics and People (pp. 75-92). ISEAS-Yusuf Ishak Institute.

Elazar, D.J. (1987). Exploring Federalism. University of Alabama Press.

Faruqi, S.S (2012). The Bedrock of Our Nation: Our Constitution. Zubedy Ideahouse Sdn.Bhd.

Harding, A. \& Chin, J. (2014). 50 Years of Malaysia. Marshall Cavendish.

Hazis, F.S. \& Kadam-Kiai, S. B. (2013). Politics and Local Government in Sarawak. Universiti Malaysia Sarawak.

Kalimuthu, K.R (1986). The Sabah State Elections of April 1985. Asian Survey, 26(7), 815-837.

Leigh, M. (2018). The Rising Moon: Political Change in Sarawak 1959-1972. Strategic Information and Research Development Centre.

Leigh, M. (2018). Deals, Datus and Dayaks: Sarawak and Brunei in the Making of Malaysia. Strategic Information and Research Development Centre.

Means, G.P. (1968). Eastern Malaysia: The Politics of Federalism. University of California Press.

Neilson, I.M. (2017). Realignment of State-Centre Relations: The Adenan Factor in Sarawak. Southeast Asians Affairs, 221-231.

Oswald, K. (2017). Federalism without Decentralization: Power Consolidation in Malaysia. Journal of Southeast Asian Economies, 34(3), 488-506.

Ritchie, J. (1987). Sarawak: A Gentleman's Victory for Taib Mahmud. Selangor: Pelanduk Publications (M) Sdn. Bhd.

Suruhanjaya Pilihanraya Malaysia (2021). Laporan Keputusan Akhir Dewan Undangan Negeri bagi Negeri Sarawak tahun 2011 dan 2016 (https://www.spr.gov.my/ms/keputusan-pilihan-raya, diambil pada September 3, 2021)

Tarlton, C. (1965). Symmetry and Asymmetry as Elements of Federalism: A Theoretical Speculation. The Journal of Politics, 27(4), 861-874.

Woon, W. (2012). Single Party Dominance in Sarawak and the Prospects for Chance. Contemporary Southeast Asia, 34(2), 274-295.

Yusof, M.A dan Agustino, L. (2011). Federalisme di Malaysia: Potret Hubungan Pusat Daerah. Analisis CSIS, 40(2), 193-216.

Yusoff, M.A. (2001). Sabah Politics under Pairin. Journal of Southeast Asian Studies, 6, 29-48. 